\title{
Mothers in an Insider-Outsider Economy The Puzzle of Spain
}

\author{
Paula Adam \\ European University Insitute, Department of Economics \\ 50016-San Domenico di Fiesole (FI), Italy \\ and \\ IGIER, Abbazia di Mirasole \\ 20090 Opera (MI), Italy \\ igie2fe@uni-bocconi.it
}

March 1996

\begin{abstract}
This article analyzes married women's labour force transitions in a Male Breadwinner Regime in the context of an Insider-Outsider economy. The argument of the article is that transitions behave differently when wives are in insider rather than outsider households, and when they are long-run participating wives rather than a priori non-participant wives. In other words, the puzzle is that the standard predictions of women's behaviour in a Male Breadwinner regime may not apply if the initial conditions change: 1) mothers may not respond as expected if they are in outsider households, and 2) highly educated mothers may not respond as expected if they studied because they intend to participate in the long run. The model is a simple Transition Model that assumes a First Order Markov Process. This model is convenient because it allows us to capture mover-stayer effects in combination with effects promoting participation and promoting inactivity. Spain turns to be an ideal case to apply the analysis. The data used is the Household Income and Expenditures Survey (ECPF, 1985-90).
\end{abstract}

\section{Acknowledgements}

This article is inspired on an earlier article, published in Spanish (Adam 1995a). I acknowledge financial support from the Bank of Spain (Fondo para Estudios sobre el Mercado de Trabajo), and thank the comments of its anonymous referee. This earlier article also benefitted from financial support from CIRIT, Generalitat de Catalunya. Regarding the final version of this article, I thank the participants in the session on Women's Labour Force Transitions in the ESPE ninth annual meeting at Lisbon, the participants in the IESA (CSIC, Madrid) seminar, the participants in the session on European Labour Markets in the IEA meeting at Tunis, the participants in the IGIER seminar, Namkee Ahn, Siv Gustafsson, Andrea Ichino, Sergi Jiménez and Robert Waldmann for comments. My very especial thanks go to my thesis supervisor, John Micklewright, to Gosta Esping-Andersen, John Myles, Dennis Snower and David Soskice. 


\section{Introduction}

There is growing evidence that childcare and maternity leave provisions have a positive impact on married women's labour force participation. Gustafsson et al (1994) distinguish two policy models: the traditional Male Breadwinner Model which encourages women to withdraw from the labour force after childbirth, and the Individual Model which encourages female re-entry. This difference has been studied in several comparative analyses applied to US and Northern European countries (see Gustafsson et al (1994), Gustafsson et al (1995), Ondrich et al (1995), Sundstrom et al (1995)). The central point of this article is that the behaviour of women subject to "male breadwinner" policies may not be as expected when unemployment and job insecurity among "male breadwinners" is high.

Insider-outsider economies are ideal to investigate this issue. The polarization of the labour force in these economies is often reflected through the levels of labour force rotation and mobility: insiders (with high employment security) usually enjoy long tenure, while outsiders (with low employment security) often shift between intermittent episodes of employment and unemployment. In this context, "male breadwinner" policies are likely to be less effective among outsider households: women may compensate for the household's employment uncertainty, probably with intermittent episodes as well. Among insider households, the response of highly educated mothers to "male breadwinner regimes" may not be as expected if women study because they intend to participate over the entire life-cycle. Highly educated women usually have high real wages which allows dual earner households to afford alternative sources of child care.

Spain is a suitable case to investigate this issue. Its design of social policies towards working mothers resembles closely the breadwinner model in the sense that women are not encouraged to return to work after maternity leave. However, in Spain employment is not guaranteed for a significant proportion of the population. On the one hand, male, female and 
youth unemployment rates are the highest among OECD countries and, on the other hand, job stability has become highly polarized since the early 1980s between insiders (with permanent contracts) and outsiders (with fixed term contracts). In this context, one would expect the "male breadwinner" policies to be more effective among wives in insider households, than among wives inserted in households with weak job guarantees.

The paper is organized as follows. In Section 2 I describe the recent trends in female labour participation in Spain. Section 3 examines the Spanish "Male Breadwinner Regime" comparatively. Section 4 describes employment and unemployment trends, and the institutional factors that have favored an insider-outsider polarization in Spain. Section 5 is devoted to the empirical model and its interpretation. Section 6 describes the empirical results, and Section 7 concludes.

\section{Female Labour Force Participation}

Traditionally, female labour force participation in Spain has been among the lowest in the OECD. Participation has risen since the 1970s by an annual average of 0.4 , which is lower than in other OECD countries. Nevertheless, in the mid 1980s the growth in female labour force participation has been substantial. Between 1985 and 1992, it rose from $34.8 \%$ to $43.6 \%$ (e.g. an annual average increase of 1.3 points). This increase is more striking among young population groups (excluding those in education, aged <25). Indeed, for the age group 25-49 participation rates increased 6.3 points on average from 1984 to 1992 . Had all entering women actually found jobs, they would have absorbed $70 \%$ of all job creation. This occurred during a period when the average unemployment rate was around $20 \%$.

Some authors conclude that this female participation growth has been promoted by a cyclical effect (encouraged worker effect), given the great employment creation during the second half of the 1980s (see Novales (1989), Albarracin and Artola (1989), Novales and Mateos (1990)). However, there are indications that long term secular trends may be even more important (see Adam, 1995b). The large increase in female participation in the 1980s was 
accompanied by: 1) a structural change in the demand for labour which favored female employment; and 2) a change in women's life-cycle behaviour, reflected in delayed entry into the labour market due to human capital investment, in higher participation rates after marriage and childbirth, and in decreasing fertility. The key piece of evidence is Arellano and Bover's (1994) time series estimation. Although they find a significant business cycle effect, they conclude that the main effect is due to structural shifts in female earnings potential. Given these results, the predictions of Arellano and Bover are that: "[..] the levels of prime age female participation that have been reached and that were never experienced before are here to stay. Even if these levels remain constant in the future, we would expect the total participation rate to increase due to replacement of older cohorts" (1994:21).

Despite the new life-cycle participation profile (especially among highly educated women) and the increase in participation among younger cohorts, female participation rates are still the lowest among OECD countries. This suggests that there is one group of women who $a$ priori intend not to work; I shall call these a priori non-participating women in the case that they do participate. Another group of women intends to remain permanently employed. This group I will call long-run participants. This distinction is used in this research to examine: 1) the response to the "male breadwinner regime", and 2) the response to husband's employment situation within these two different groups of women.

\section{The Spanish Male Breadwinner Regime}

Table 1 shows that in countries with different childcare and parental leave regimes ${ }^{1}$ mothers' employment rates differ sharply by age of youngest child. In Sweden there is an extensive programme of universal daycare and maternity leave (65 weeks). In the US there is very little public support for child care (except for tax credits that mainly benefit lower-middle income groups) and no paid or unpaid parental leave. As a result, Swedish women tend to re-enter the labour force after maternity leave, while American mothers tend to return to work immediately after childbirth. The participation rate among Swedish mothers with children under age 1 is

\footnotetext{
${ }^{1}$ See OECD (1990) for a detailed description of the child care regimes in OECD countries.
} 
almost 40 percentage points lower than among women with older preschoolers. In the United States, the difference in employment rates of women with the younger child less than one and more than one is about 10 points. In the Netherlands, maternity leave provision provides $100 \%$ of the previous wage for 16 weeks and there is no substantial daycare provision. Thus, the difference in employment rates of women with the younger child less than one and more than one is less than 5 points. The lack of substantial daycare seems to affect experience loss, reflected in the employment rates of mothers with schoolers: once the youngest child arrive at school age, employment rate among Swedish mothers increases almost 10 points, while among Dutch mothers decreases in 3 points.

Table 1

Working Mothers (\%) by Age of Youngest Child

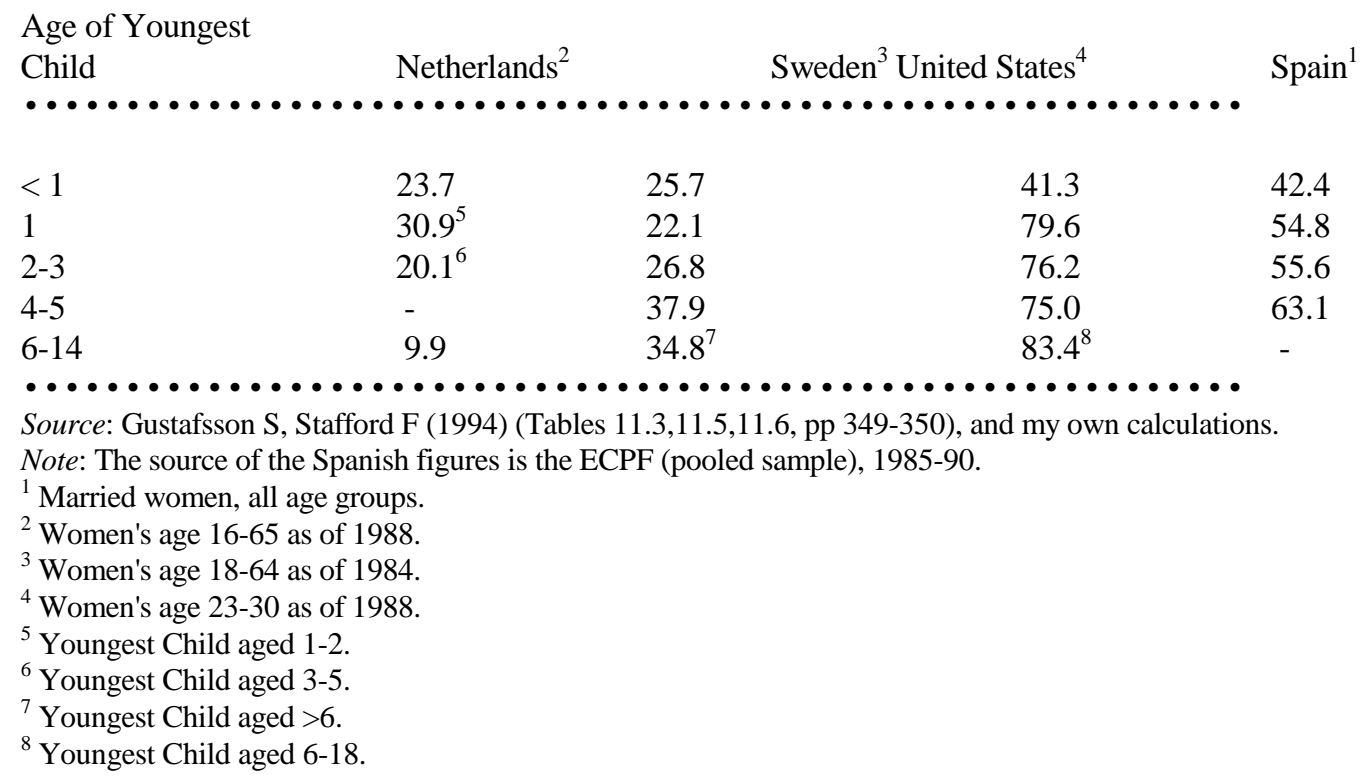

Regardless of (optional) separate income taxation in the household and some public provision for mothers with pre-school children, Spain lies close to the Male Breadwinner Model. Maternity benefits provide $75 \%$ of previous wages for 14 weeks $^{2}$. After the first three

\footnotetext{
${ }^{2}$ Maternity leave depends on participation in the social security system, and on payment of taxes during the previous 6 months.
} 
months there is no national policy and daycare services are very limited (including local commune daycare). The lack of substantive daycare provision reduces the incentives for women with pre-school children to enter the labour force. Nevertheless, previously employed mothers do make use of maternity leave. Seventeen percent of mothers with a child less than 3 months are at work compared to $23.3 \%$ of mothers with one child aged 4-12 months (Spanish Income and Expenditures Survey, ECPF, pooled data 1985-90).

Once the children arrive at school age (6 years), the incentives for Spanish mothers to return to work are not very strong even if schooling is compulsory and free of charge. On the one hand, although the Spanish school day is usually long (8 hours per day, from 9am to 5pm) this still poses an obstacle for women to return to work because, unlike in other OECD countries, part-time contracts are rare (see OECD, 1994). On the other hand, the loss of experience during maternity absence might be quite significant. However, even if the Spanish childcare regime is similar to that of the Netherlands, differences in employment rates by age of youngest child differ tremendously, particularly for mothers with schoolers, but also for older pre-schoolers. This obvious difference suggests the existance of cohort effects (reflected through the age of youngest child) dictating mothers' behaviour.

The different pattern of mothers' employment in Spain compared to other countries with similar regimes suggests the existence of other factors influencing Spanish mothers' behaviour. On the one hand, a cohort effect (reflected through the age of youngest child) might dictate Spanish mothers' behaviour. On the other hand, as I describe in the following section, the costs of prolonged labour market absence may be especially high in an "insider-outsider" economy like the Spanish.

\section{Employment and Unemployment, Insiders and Outsiders.}

Female unemployment in Spain, conventionally measured as percentage of the labour force, is very high: $28 \%$ in 1987, and 24\% in 1990 (according to the labour Force Survey, which is a more optimistic source than the Employment Office data bank). In spite of the scarcity of part- 
time female work ${ }^{3}$, atypical employment is now widespread in the form of temporary contracts (i.e fixed-term contracts with low firing costs, only renewable through permanent contracts) as a result of new legislation introduced in 1984. The proportion of female "temporaries" rose from $18.4 \%$ of female wage employment in 1987 to $34.2 \%$ in 1990 , the highest level in the OECD area. Because of expected long periods of absenteeism employers are more likely to favor temporary over permanent contracts for women. The result is a large increase in female labour rotation ${ }^{4}$.

But temporary contracts are also widespread among (young and adult) men. The debate in the Spanish economic literature about the implications of the extensive use of temporary contracts focuses mainly on its impact on wage setting, and on access to stable employment. It is often concluded that temporary contracts have introduced more rigidity to the system because they create more stability and bargaining power for the permanent workers, and more job volatility within the rest of the population [Bentolila and Dolado (1994), Jimeno and Toharia (1993)]. Indeed, before 1984 Spain had the longest average jobs tenure in the OECD, and short term rotation levels were below the OECD average. Seven years later, average tenure remains among the longest in the OECD, but the percentage of workers with less than one year's tenure has, concomitantly, grown tremendously. This, in combination with high unemployment, is consistent with the argument that the Spanish workforce has polarized into an insider and outsider group in terms of access to stable employment and job security [see Lindbeck and Snower (1988)]. Revenga (1994) describes the existence of a bimodal distribution, with a large number of workers enjoying long tenure (18.4\% have more than 20 years tenure) and a growing number of workers with short term turnover (rising from $15 \%$ in 1987 to $24 \%$ in 1991). Although the increase of workers with brief tenure may also be due to the recent inflow of new workers, the relationship between the implementation of temporary contracts and employment rotation is clear: only $17 \%$ of temporary workers in any year made a transition to permanent contracts one year later (Segura et al, 1991). Given that temporary contracts cannot be renewed

\footnotetext{
${ }^{3}$ Spain is the only OECD country (along with Italy) where the proportion of female unemployment is larger than the proportion of part-time employed women.

${ }^{4}$ The proportion of female workers with short-term (less than one year) tenure was $27 \%$ in 1991.
} 
with another temporary contract by law (AES), this often implies a transition to unemployment. Moreover, before 1992 temporary workers were entitled to unemployment benefit for up to half time of their tenure with a tax-free benefit equal to $80 \%$ of previous salary. This gave incentives to some workers to search for short term jobs, followed by intermittent episodes of unemployment [see Bentolila and Dolado, $1994^{5}$ ]. Therefore, temporary contracts seem to be the main cause of the increased labour rotation with intermittent employment among the outsiders.

Within households, the dualisation of the Spanish labour market during the second half of the 1980s has introduced employment uncertainty. If married women are sensitive to the labour and income expectations of the household, they may accept paid jobs to compensate for household uncertainty. Two factors suggest that these are likely to be unstable jobs. One, outsider household breadwinners are likely to be inserted in environments with weak labour market networks, which therefore lowers the probability that the wife finds a stable and/or insider job. Two, household work is usually carried out by wives, and finding substitutes often implies too high costs. Therefore, if women combine household and market work, their available time often restricts them to irregular jobs, i.e high rotation. In this case, women will complement the mobility of other household members with their own mobility. These women are active on the margin because they keep a marginal attachment to the labour force, typically characterized by intermittent episodes of employment and inactivity, usually as a response to fluctuations in husband's employment and income. Thus, the labour force rotation of married women may very well be due to a compensation and cyclical effect.

To conclude, married women's mobility may be the result of two separate forces, one which is distinct for long-term participating women, another for short term participating women. In the first case, turnover of a priori active women (usually with high education) should be similar to men, although there are differences when it comes to aspects such as maternity (which also affects mobility). In the second case, mobility of a priori inactive women living in

${ }^{5}$ Bentolila and Dolado (1994) note that since the implementation of the AES law, the number of unemployed entitled to unemployment benefit has increased, which is consistent with the reduction of unemployment duration and with the increase of labour rotation. 
households with an "outsider" breadwinner may have increased in tandem with the increasing polarization of the Spanish workforce.

\section{The Empirical Model}

\subsection{Standard Participation Probability Model}

Let us assume a linear participation function in reduced form $\mathrm{g}=\mathrm{Ax}_{\mathrm{it}}+\mathrm{Bz}_{\mathrm{i}}+\mathrm{u}_{\mathrm{it}}$ for wife $i$ at time $t, i=1, \ldots N, t=1, \ldots T$. The observed vectors of time-variant variables $\mathrm{X}_{\mathrm{it}}$ and time-invariant variables $Z_{\mathrm{i}}$ are assumed to be exogenous and include factors that affect the reservation wage and market wage values of wife $i$ at time $t$ (see Deaton and Muellbauer (1984)). The error term $\mathrm{u}_{\mathrm{it}}$ includes the unobserved time-variant and time-invariant factors. Typically, the reservation wage value depends on factors such as tastes for use of non-market time, fixed costs of participation such as childcare, wife's individual characteristics, household non-labour income, husband's earnings, etc. The market wage value depends on factors that determine wives's expected salary in the current labour market, such as wife's education and labour market experience, a given policy she faces, the regional price index, and other economic indicators such as the local unemployment rate.

Let us assign values 0 and 1 to the two possible labour market states (participation and non-participation in the labour force), and define a sequence of binary random variables:

$$
\begin{array}{rll}
\mathrm{y}_{\mathrm{it}} & =1 & \text { if } i \text {-th person participates at time } \mathrm{t} \\
& =0 & \text { otherwise }
\end{array}
$$

In other words, $\mathrm{y}_{\mathrm{it}}=1$ if $\mathrm{g}>0$ and $\mathrm{y}_{\mathrm{it}}=0$ if $\mathrm{g} \leq 0$. The probabilistic binary choice model can then be defined as follows:

$P\left(y_{i t}=1\right)=P(g>0)=G\left(A x_{i t}+B z_{i}\right)$ 
$\mathrm{P}\left(\mathrm{y}_{\mathrm{it}}=0\right)=\mathrm{P}(\mathrm{g}<0)=1-\mathrm{P}(\mathrm{g}>0)=1-\mathrm{G}\left(\mathrm{Ax}_{\mathrm{it}}+\mathrm{Bz}_{\mathrm{i}}\right)$

where $\mathrm{G}$ is the associated probability distribution of $\mathrm{g}$.

\subsection{Transition Probability}

The central objective of this article is to analyze the flow between participation and inactivity for married women in any given period. The essential tool for this analysis is the transition probability. That is, the probability of moving from one labour market state to another during a given time interval. With discrete time data, Transition Models are a good choice ${ }^{6}$. A particular case is the discrete-state, discrete-time Markov Model with exogenous variables, which is represented by the parametric analysis of discrete states under the general assumption that an individual' choice of labour market state can be viewed as a first order Markov process. This model is a natural extension of the static qualitative choice model to a dynamic context, where changes in labour market states occur over time as a result of either changes in stochastic characteristics of the individual or the environment, or simply due to individual characteristics which define a mobility propensity.

I shall consider a Two-state First Order Markov Model with exogenous variables over T periods as described in Amemyia (1985). The transition probability between state 0 and state 1 can be specified as a conditional probability of the form:

$$
\mathrm{P}_{01}^{\mathrm{i}}(\mathrm{t})=\mathrm{P}\left[\mathrm{y}_{\mathrm{t}}^{\mathrm{i}}=1 / \mathrm{y}_{\mathrm{t}-1}^{\mathrm{i}}=0\right]
$$

and similarly,

$$
\mathrm{P}_{10}^{\mathrm{i}}(\mathrm{t})=\mathrm{P}\left[\mathrm{y}_{\mathrm{t}}^{\mathrm{i}}=0 / \mathrm{y}_{\mathrm{t}-1}^{\mathrm{i}}=1\right]
$$

\footnotetext{
${ }^{6}$ See Amemiya (1985) for a description of this group of models.
} 
which is the conditional probability of transition from state 1 and $0^{7}$. The probabilistic specification showed in (3) can be parametrized by introducing a distribution function which depends upon exogenous variables, and which accounts for heterogeneity and non-stationarity of the data. How to specify this function? Given the probabilistic model in (2), the transition probabilities of (3) can be expressed as:

$$
\begin{aligned}
& P_{01}^{i}(t)=\frac{P\left(a X_{i, t}+b Z_{i} \leq 0, a X_{i, t-1}+b Z_{i} \geq 0\right)}{1-G\left(a X_{i, t-1}+b Z_{i}\right)} \\
& P_{10}^{i}(t)=\frac{P\left(a X_{i, t}+b Z_{i} \geq 0, a X_{i, t-1}+b Z_{i} \leq 0\right)}{1-G\left(a X_{i, t-1}+b Z_{i}\right)}
\end{aligned}
$$

which therefore depend on the value of the observed time-variant variables in both periods and on the observed time-invariant characteristics. Equation (4) can be expressed as a linear function in reduced form with a simple distribution function $\mathrm{F}$. The time-variant variables at $t-1$ and $t$ are included ${ }^{8}$ and measure changes in their values. The time-invariant variables are also included and capture the mobility propensity:

$$
\begin{gathered}
P_{01}^{i}(t)=F\left(\alpha \Phi\left(X_{i t-1}, X_{i t}\right)+\beta Z_{i}\right) \\
P_{10}^{i}(t)=F\left(\alpha^{*} \Phi\left(X_{i t-1}, X_{i t}\right)+\beta^{*} Z_{i}\right)
\end{gathered}
$$

${ }^{7}$ The First-Order Markov Model assumes that the distribution of $y_{\mathrm{it}}$ is not independent of $y_{\mathrm{it}-1}$, but independent of $\mathrm{y}_{\mathrm{is}}$ for all $\mathrm{s}<\mathrm{t}-1$. Under the assumption of independence of $\mathrm{y}_{\mathrm{it}}$ and $\mathrm{y}_{\mathrm{it}-1}$ the probability specified in (3) is equivalent to a simple probabilistic model of the form $\mathrm{P}\left[\mathrm{y}_{\mathrm{it}}=1\right]$, such as the participation model in (2). Moreover, Amemiya (1989) shows that the probability specification of (3) is equivalent to an unconditional specification with state dependence of one period. That is, $\mathrm{P}\left(\mathrm{y}_{\mathrm{it}}=1\right)=$ $\mathrm{P}\left(\mathrm{a}, \mathrm{b} ; \mathrm{X}_{\mathrm{it}}, \mathrm{Z}_{\mathrm{i}} ; \mathrm{y}_{\mathrm{i}, \mathrm{t}-1}\right)$.

${ }^{8}$ Time-variant variables with trivial variation, such as age, are considered as if they were timeinvariant. 
where $\alpha, \alpha^{*}, \beta$, and $\beta^{*}$ are vectors of parameters. $\Phi$ is a function that measures the changes in the observed time-variant exogenous variables from $t-1$ to $t$. The specification of $\Phi$ depends on the nature of the variable ${ }^{9}$.

The estimation procedure assumes a logistic distribution of $\mathrm{F}$. The likelihood function of the transition model is given by the distribution of the four possible events: stay in, entry, stay out and exit from the labour force. Amemiya (1985) shows that estimation of the present model can be carried out with simple logit models of the two separated hazard rates: the probability of entry (or stay out), and the probability of exit (or stay in) the labour force from $t-1$ to $t$.

\subsection{Interpretation of the Empirical Model.}

I have described a transition model with two probability equations. Transitions are modelled from time $t-1$ to $t$. The independent variables are all assumed to be exogenous in the model and measured at time $t-1$, i.e before the transition occurs. The dynamic time-variant variables are measured at time $t-2$ and $t-1$, i.e. $\Phi\left(\mathrm{X}_{\mathrm{it}-2}, \mathrm{X}_{\mathrm{it}-1}\right)$, to avoid endogeneity problems. In principle, these are included in the model specification to capture the effect of changes in these explanatory variables, e.g husband's change in employment status. Nonetheless, some timevariant variables are also included with a static specification in order to assess which provides the better fit. For example, husband's employment status is introduced as a static variable at time $t-1$, and also as a dynamic variable from $t-2$ to $t-1$. The time-invariant effects, $Z_{\mathrm{i}}$, are meant to capture fixed effects with an influence on the transition probabilities.

When the specification of the two probability equations is exactly the same, then the parameter estimates are perfectly comparable. Let us imagine a model specification with $K+J$ exogenous variables and thus $2(K+J)$ parameter estimates: $\alpha_{\mathrm{k}}, \beta_{\mathrm{j}}$ (in the entry equation), and $\alpha_{\mathrm{k}}^{*}, \beta_{\mathrm{j}}^{*}$ (in the exit equation), $k=1, \ldots K, j=1, \ldots J$. Table 2 summarizes the interpretation of the estimated effects. A negative sign in both equations indicates that the higher the effect, the

\footnotetext{
${ }^{9}$ For discrete variables such as husband's labour market status, $\Phi$ is specified as simple differences or as a dummy accounting for changes of labour market status.
} 
lower the probability of entry and exit the labour force. Similarly, a positive effect in both equations promotes mobility, as it raises the entry and the exit probability. Finally, an effect with positive sign in the exit equation, and negative in the entry equation promotes inactivity, whereas the opposite promotes participation.

Table 2

Interpretation of the Estimated Effects, according to the Sign of the Coefficient Estimates

\begin{tabular}{|c|c|c|}
\hline \multicolumn{2}{|c|}{$\begin{array}{c}\text { Sign of the Estimated Effect } \\
{\left[\alpha_{\mathrm{k}} \Phi\left(\mathrm{x}_{\mathrm{kit}-2}, \mathrm{x}_{\mathrm{kit}-1}\right) \text { and } \alpha^{*}{ }_{k} \Phi\left(\mathrm{x}_{\mathrm{kit}-2}, \mathrm{x}_{\mathrm{kit}-1}\right)\right]} \\
\text { or }\left[\beta_{\mathrm{j}} \mathrm{Z}_{\mathrm{ji}} \text { and } \mathrm{B}_{\mathrm{j}}^{*} \mathrm{Z}_{\mathrm{ji}}\right]\end{array}$} & \multirow[t]{2}{*}{$\begin{array}{l}\text { Interpretation the Estimated Effect } \\
\text { in the Transition Model }\end{array}$} \\
\hline Entry Equation & Exit Equation & \\
\hline Positive & Positive & Promotes Mobility \\
\hline Negative & Negative & Promotes Stability \\
\hline Positive & Negative & Promotes Participation \\
\hline Negative & Positive & Promotes Inactivity \\
\hline
\end{tabular}

The advantage of this model is that it allows us to estimate effects of long-run participating versus short-run participating women in combination with the insider-outsider effect, and with the effect of having childcare responsabilities. The effects that promote mobility are likely to reflect characteristics of "outsider households", such as husband's unemployment and labour rotation. The effects that promote stability are likely to capture "insider households", where women can pursue a priori participation decisions (i.e. a priori inactive wives remain non-participants, and a priori active wives remain participants). High education and employment stability among husbands are intended to capture this. Proparticipation effects capture characteristics among long-run participant women which raise the entry probability if they are temporarily out of the labour force (say, due to maternity), and which lower the exit probability. The long-run participating women are captured through a cohort effect and through husbands' high education ${ }^{10}$. Inactivity is most likely to result among the a priori inactive women (e.g older cohorts).

\footnotetext{
${ }^{10}$ As I describe in Section 6, the data used for this research (ECPF) does not provide information on wives' education (nor labour market experience). To partially solve this, I use husband's education as a
} 


\section{Empirical Results}

The data set is a pooled subsample of the Spanish Household and Expenditures Survey (ECPF), 1985-1990 ${ }^{11}$, where only households headed by married couples with wives younger than 65 are selected. With its quarterly rotating panel structure it is possible to model transitions. The data has been organized by pairs of successive interviews, obtaining 39,260 three-months' transitions related to 11,802 households. The greatest shortcoming is that there is no information on wives' education, labour market experience and wages, nor on region of residence of the household. Given the great importance of own education and experience for female participation, and the substantial regional differences (in terms of female labour supply behaviour) in Spain, these may well be relevant variables in the model. If the regressors are correlated with the omitted variables, the consequence may be biased parameter estimates. Therefore the goodness of fit of the estimated models is likely to be affected.

The sample transitions are distributed as follows: $24.1 \%$ married women participate at time $t-1$. Among these, $8.4 \%$ make an exit transition and $91.6 \%$ stay at time $t$. The other $75.9 \%$ married women are non-participants at time $t$-1. Among these, 3.2\% make an entry transition, and $96.8 \%$ stay at time $t$. Table 3 shows the cross-distributions of participation (in $\%)$ at time $t-1$ and at time $t$. The off-diagonal cells report the transition rates and the diagonal cells show the stay rates.

proxy, since husband's and wife's schooling may well be correlated. In fact, other data sources have yielded a correlation coefficient 0.60 (Source: Encuesta de Biografía y de Clase, 1991, data kindly provided by Olga Salido). In turn, the husband's education variable also measures the labour market position of the husband (given that men's labour market stability increases with age). The need to use proxies is almost certainly the main reason for the very poor fit in the model tests I present below.

${ }^{11}$ The reader is referred to Adam (1995c) for a description of the ECPF survey and a discussion of its uses for labour market research. 
Table 3

Married Women's Labour Force Transitions in the ECPF Pooled Subsample

Destination State, time $t$

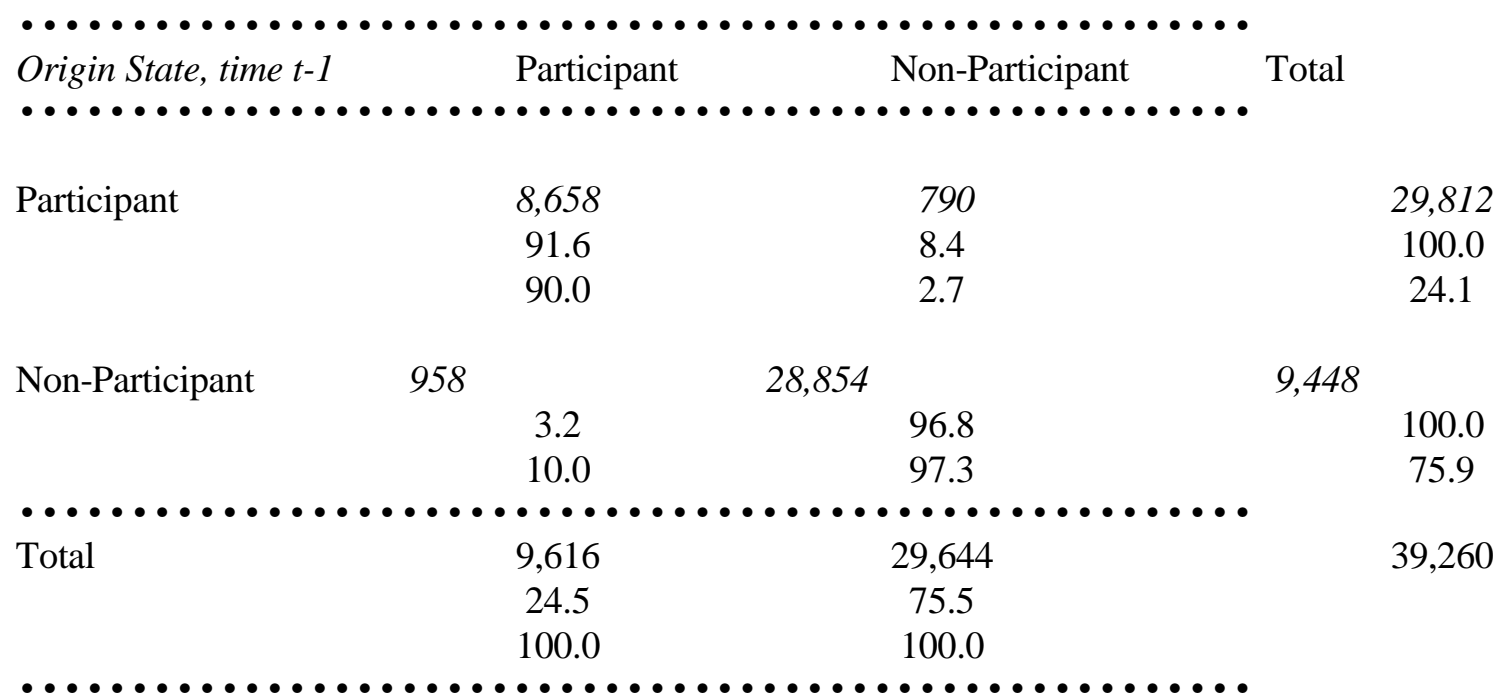

Note: Cells are organized as normal contingency tables. The first figures (in italics) are the raw numbers. The second are the row percentages and the third are the column percentages.

The estimation strategy is the following. The same specification is imposed in both the entry and the exit probability equations to obtain perfectly comparable estimates. In terms of goodness of fit of the model, the cost of this strategy is that some irrelevant variables are kept in the specification. Although this does not bias the coefficient estimates, the model looses precision if the irrelevant variables are correlated with other variables in the model specification. The results concerning life-cycle effects are included in Table 4, together with other control variables. Because the time-variation of these variables is trivial, I treat these as time-invariant variables. The effects of children are reported in Table 5, with two different specifications. Again, the time variation of these variables is trivial and therefore these are treated as time-invariant. The exception is the birth of a child. The effects of husbands' labour status (time-invariant specification) are presented in Table 6. Then the effects of husbands' labour market transitions (time-variant specification) are presented in Tables $7 \mathrm{a}$ and $7 \mathrm{~b}$. Descriptive statistics are in the Appendix. 
As a first approximation of a life-cycle effect, I examine the age effect on wives' transitions. A correct specification for wives' age is not straightforward, because the exit rates by wives' age follow a u-curve (reaching around 13\% rates in the extremes and $6 \%$ as a minimum at the age of 35-39). This suggests that a quadratic specification would be reasonable. However the entry rates follow a rather decreasing flat curve, suggesting a linear effect. It turns out that linear and quadratic specifications perform poorly when imposed simultaneously in both equations. I have solved this by using a linear spline function specification ${ }^{12}$, because it provides a more flexible alternative to quadratic and linear specifications.

The interpretation of the coefficients in the entry equation is the following: a negative sign shows that as age increases, wives are less likely to enter the labour force. As age increases in one year, the entry probability of women aged $30-40$ decreases ${ }^{13} 1.5 \%$, while for women aged 40-50 the entry probability decreases $2 \%$ and for women over 50 , it decreases $1.7 \%$. Tests for equality of the parameter estimates "wife's age 30-40", "wife's age 40-50" and "wife's age >50" have not been rejected, which suggests that women have less incentives to enter after the age threshold of 30 . Thus, the marginal impacts are quite small and of the same size. What about the size of the effects itselves? These are fairly big and, as commented later, bigger than other effects such as cohort effects or husbands' education (except for wives older than 35). In the exit equation, wives' age parameters are not significant, except "wive's age $30-40 "$ with negative sign. This means that participating wives are less likely to exit at age 40 than at age 30 . In this case, the age penalty on the entry probability is $1.9 \%$. The obtained

\footnotetext{
${ }^{12}$ See Johnson (1984) and Greene (1993) for good descriptions of piecewise specifications (in the form of linear spline functions).

${ }^{13}$ In the text, I report the effect $\alpha \mathrm{X}$, but not the final marginal impact on the participation probability (i.e the derivative of the participation probability $\mathrm{P}$ with respect to an explanatory variable $\mathrm{X}$ with coefficient $\alpha$ ). With logit functional forms, the final marginal impact is:

$\mathrm{dP} / \mathrm{dX}=\mathrm{P}(1-\mathrm{P}) \alpha$

For different values of $\mathrm{P}$ one obtains different marginal impacts. If $\mathrm{P}=0.5$, then division of each coefficient by 4 (e.g $\alpha \mathrm{X} / 4)$ shows the maximum marginal impact.
} 
coefficient estimate is not significantly different from the ones obtained in the entry equation. Note that holding other effects constant, the probability levels are just below 0.5. The negative sign in the entry and exit equations suggests the existence of an effect promoting stability, which is larger at age 40 than at age 30 . This stability effect is an interesting finding but difficult to interpret in isolation. Other issues related to this period of women's life-cycle must be examined before making conclusions. Factors such as cohort membership, childbirth and a greater incidence of fixed-term contracts among women aged 30 than 40 are all likely to play a role. These are discussed below.

Considering the evolution of female participation in Spain, one can expect substantial cohort differences. According to Arellano and Bover (1995), the cohort of 1951-60 is the first to experience a significant jump in married women's participation rates. In the model specification of Table 4 , the dummies capturing 4 different cohorts ${ }^{14}$ (the base is: cohort 1921-30) show that, indeed, the 1951-60 and the subsequent cohort (i.e. 1961-1973) have a large negative coefficient in the exit equation: setting all other effects to zero, the 1951-60 cohort (relative to the 1921-30 cohort) lowers the exit probability by 32\%, and the 1961-73 cohort lowers the exit probability 29\% more than the 1921-30 cohort. Note that older cohorts show no significant effects. The entry probability is clearly not affected by cohort effects, implying that differences between younger and older cohorts do not have to do with entry but with withdrawal from the labour force. Note that these cohorts are aged 20-40 during the years of the ECPF survey (1985 to 1990). Comparing the coefficient estimates, the cohort effect seems to be stronger in reducing the exit probability.

${ }^{14}$ Cohort effects have also been approached with piecewise linear specifications. The resulting coefficient estimates turn to be quite similar to those obtained with simple dummies. For simplicity, I decided to show in Table 4 the later specification instead of the former. 


\section{Table 4}

\section{Logit Model of Transition Probabilities}

The Cohort and Age Effects, and Husband's Education and District Size Effects

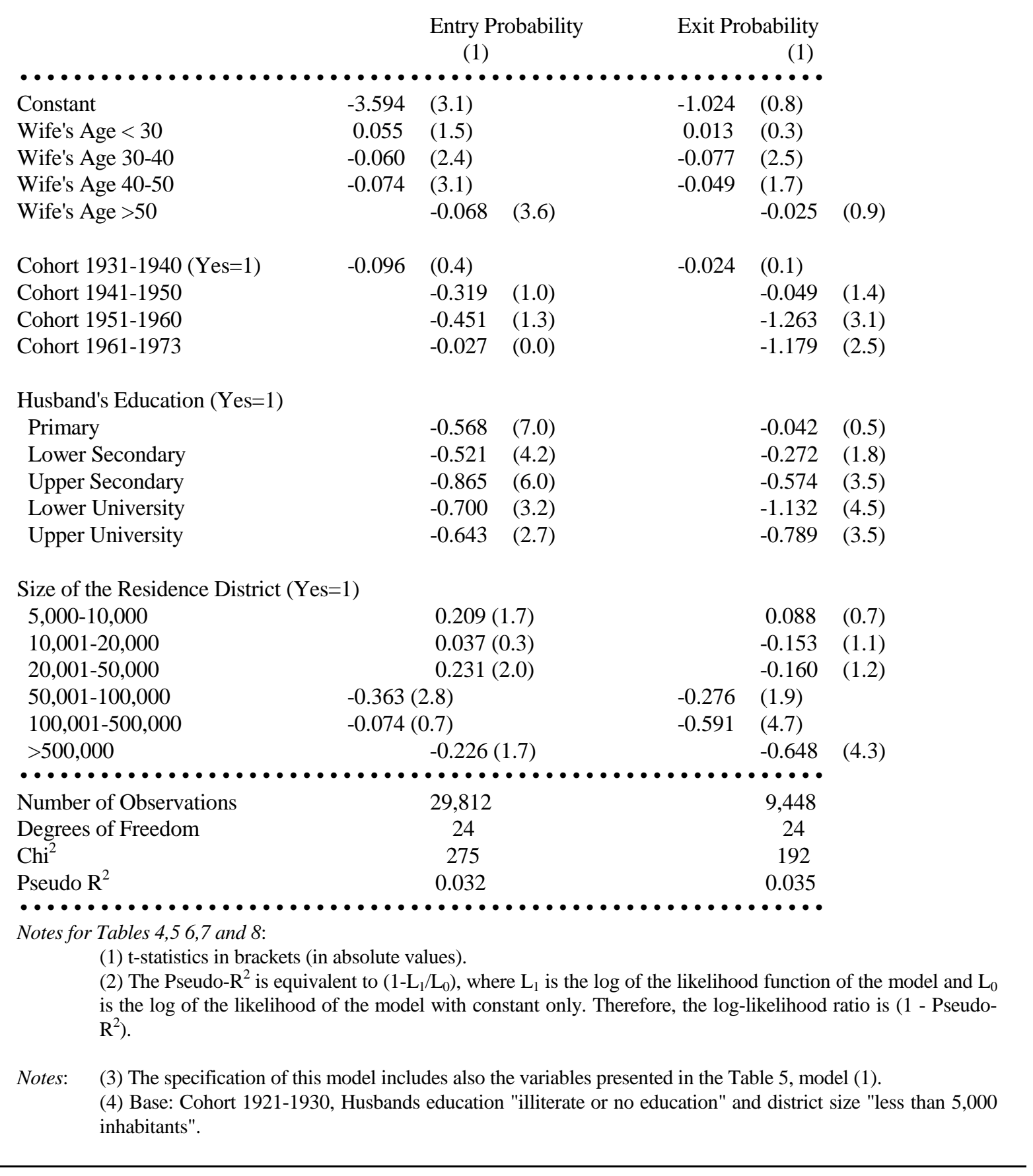


The structural change found by other authors is, therefore, consistently reflected in either the delay or the permanence of younger cohorts in the labour force. Whether this cohort effect reflects a delay (i.e. exits take place at older ages, probably due to delays in fertility

or fertility decline) or permanence (i.e. a large proportion of women intend to stay in the long run) is something that can only be empirically assessed only in the future, when the cohorts 1951-60 and 1961-73 will reach the post-fertile ages, or through the analysis of the relevant effects on the entry probability.

The life-cycle participation profile of women (like men) is clearly marked by the duration of education. Women's entry in the labour market depends on length of studies. Moreover, it is an universal finding that women's education is positively correlated with participation. This is particularly relevant in Spanish research (Arellano and Bover (1994), and Martínez (1994)). The proportion of highly educated women has increased tremendously, from $20 \%$ in 1976 to $63 \%$ in 1992 (Adam, 1995b). Therefore, education is expected to affect transition probabilities, delaying first entry and reducing exits. Unfortunately, there is a lack of information on wives' education and I must use as proxy husbands' education. In principle, the inclusion of this variable should not bias the results unless there is a high correlation with other variables included in the model ${ }^{15}$. I shall comment here on the obtained estimates and will later return to the issue.

Husband's education has been specified using six dummies, where "no education or illiterate" is the base. The effects on the entry probability are fairly large and all negative. So are the effects of university education and upper secondary school on the exit probability, suggesting a stability effect for wives married to men with university degree and to men with

${ }^{15}$ I have performed the same model estimations without including husband's education and the results do not change significantly. 
upper secondary school, relative to women married to illiterate men. The size of these effects is much larger than the age effects. Specifically, the probability of entry is $21.5 \%$ stronger if the husband has upper secondary school degree than if he is illiterate; $17.5 \%(16 \%)$ if he has lower (upper) university degree; and 14\% (13\%) if the husband has only primary (lower secondary) school. Note that tests for equality of primary and lower secondary, and lower and upper university have been performed and not rejected. Therefore, relative to wives of illiterate husbands, wives of upper secondary school husbands are less likely to enter than wives of university degree husbands, which in turn are less likely than wives of lower secondary or primary school husbands. In the exit equation, only upper secondary and university education have significant effects. Being married to an university degree man relative to an illiterate lowers the exit probability two times more than if married to an upper secondary school man. Hence, husband's education promotes stability, and being married to a secondary school husband lowers more the entry probability and lowers less the exit probability than being married to an university men. Despite the exclusion of direct effects of education, the indirect effects confirm the hypothesis that more education lowers the exit probability and favors more participation (in spite of the negative signs).

\section{The Effects of Children}

The strong negative correlation between the presence of young children in the household and female labour supply is a general finding in the literature (Browning (1992), Nakamura and Nakamura (1992), and Lehrer and Nerlove (1986)). This correlation is less negative as children age and cost of alternative supervision and care falls (Gustafsson and Stafford (1994)). To capture this, measures such as "age of youngest child" together with "total number of children" are universally accepted as a good specification in female labour supply estimations (Browning, 1992). I shall now discuss the problems involved with measuring the costs of supervision and child care and the obtained results, and then discuss the direct effects of children.

One problem most surveys have is the lack of information on the costs of all the types of child care potentially available to a given family. One solution is to employ proxies for 
child care costs. Heckman (1974) uses "residence in an urban area" variables to allow for the "availability of low-cost care from relatives and friends living nearby". This approach may work for the US, where rural families live more isolated, but is certainly not the best for Spain, where rural families stay close to relatives. Other authors use "residence in the same area" variables under the assumption that all families living in a given area face the same child care cost and availability environment. This should, in principle, be a better measure for the Spanish case.

My model estimation cannot control for "area of residence" because the ECPF does not provide regional information. A less satisfactory solution is to use information on "size of the residential district". This has the inconvenience that, one does not know whether it refers to a rural or urban areas ${ }^{16}$, and the geographic region of residence is unknown. As in many other countries, female participation patterns vary significantly among different Spanish regions (see Van der Laan, 1995). To include "size of residential district" in a female labour supply model is therefore ambiguous, as it may well capture other effects such as economic structure. Browning suggests that "consistency requires that we should cross these proxies with the children variables and not simply include them as additional right hand side variables (1992, p 1459)". However, I prefer to retain it as a discrete control variable because the ambiguity may become multiplicative in an interaction specification.

The resulting coefficient estimates are included in Table 4, where the base is a "districts with less than 5,000 inhabitants", and the model includes the other 6 dummies. In the entry equation, only the dummy "district with 50,000-100,000 inhabitants" has a significant negative parameter estimate, meaning that women in these districts are less likely to enter, relative to women in the smallest districts ( $>5,000$ inhabitants). For districts bigger than 100,000 , there is no significant effect in the entry equation. Rather, the exit equation shows significant results. A test for equality of the two coefficient estimates ("district size $100,000-500,000 "$, and "district size $>500,000 "$ ) is clearly not rejected. Note that its size is

${ }^{16}$ The category "district with more than 500,000" inhabitants refers to the two bigger cities: Madrid and Barcelona. Therefore, for this particular category one has more detailed knowledge of the characteristics of the area. 
not significantly different from the effect of husbands' secondary education in the same equation. Given the size and negative sign of the coefficients, it turns out that wives living in districts bigger than 100,000 are 15\% less likely to exit than wives living in the smallest districts (on average). Interpretation of this findings is difficult with the little information available on the districts. Nonetheless, the results support the hypothesis that alternative sources of child care are more available in big cities than in the smallest districts.

Turning to the direct effect of children, a general finding in the female labour supply literature is that women are sensitive to the incentive effects that different policy regimes create. In Spain, the exit would be most likely incentive response in the case of preschool children. Moreover, previously working mothers are expected to make use of maternity leave. Preschool children are likely to lower the entry probability but, for long-run participating women, school age children may rise the entry (re-entry) probability.

Model (1) in Table 5 includes the variable "total number of children" and a set of dummies representing childbirth from $t-1$ to $t$, and the age of youngest child. As expected, childbirth has a large effect on the exit probability (note that so far this is the first found positive effect). However, the age of youngest child has no effect on exit, whereas the total number of children has a positive effect (but smaller than the childbirth effect). Hence, it appears that children affect mothers' withdrawal in two ways: at birth and by being numerous. In the entry equation, none of the covariates are significant, not even "youngest child of school age $(\geq 6)$ '. This suggests that entries or re-entries in the labour force are not driven by children status or age. This result goes against what expected. Experiments with alternative specifications have been performed to assess the obtained results. Using variables accounting for the number of children of different ages does not improve the model.

One explanation for these surprising results could be that I included a priori participating and a priori non-participating women in the same class. Interaction of cohort and children is not a good way to control for this because the structural change clearly does not affect all women born after 1950's in the same way. Rather, an interaction for wives' education and children is a better specification. Because of lack of information, I use 
husband's education as a proxy. The results are shown in model (2) in Table 5. Several interesting results emerge. On the one hand, now most of the coefficients in the exit equation are significant, and the few insignificant effects all pertain to medium education husbands. More interesting, while all coefficients concerning low educated husbands are negative (and decrease with the age of youngest child), for the case of university husbands these turn all to positive signs (and the size increases with the age of youngest child) in the exit equation. That is to say, the effect of having a youngest child of pre-school age raises the exit probability among women married to low educated husbands (but the older the preschool child the lower the positive impact) while it lowers the exit probability among women married to university husbands (and the older the preschool child the more it lowers the exit probability). Note that the positive effect of children among women married to low educated men is the first positive impact found in the exit probability of all the effects considered in Tables 4 and 5. 
Table 5

Logit Model of Transition Probabilities

The Effects of Children

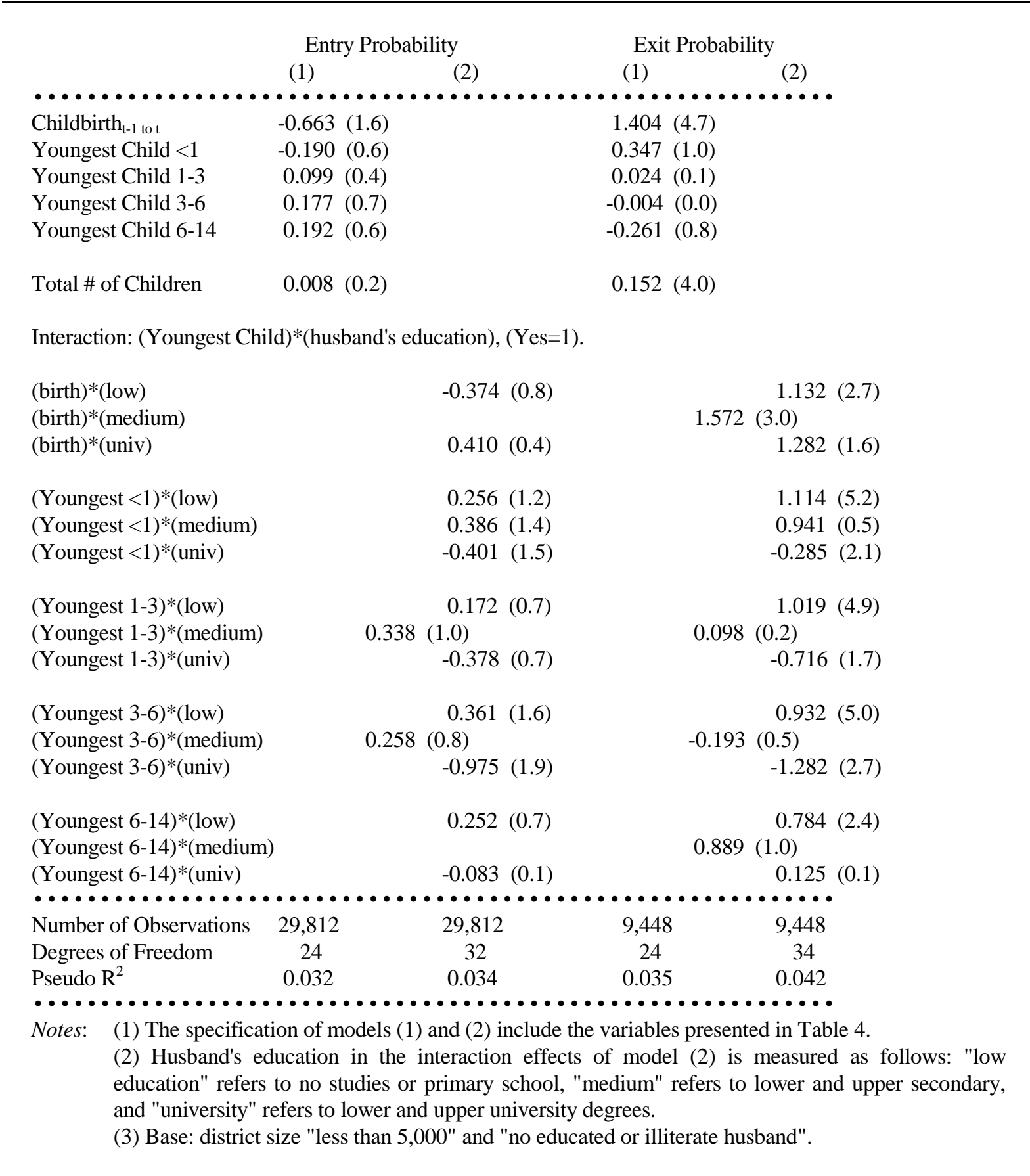

With regard to the entry equation, the results are also very interesting. The fact that none of the estimated parameters for pre-school children are significant is not surprising 
(given the Spanish social policy towards mothers) and supports the idea that social policies have an effect on the labour market transitions of women. What is really surprising is the totally insignificant effects obtained for youngest children of school age. This result is rather different to what one would expect according to the Spanish policy design. Unlike in other OECD countries, Spanish mothers do not seem to return to work after the youngest children arrives at school age.

In sum, like in other OECD countries, children are an important cause of mothers' withdrawals from the labour force, but only among women married to low educated husbands. Unlike other OECD countries, children have no effect on the entries or re-entries. Concerning mothers married to university husbands the presence of pre-schoolers do not raise the exit probability, but rather reduces it. I used husbands' education to proxy wives' education (recall that there is a correlation coefficient of 0.66 , using other data sources) and it successfully turned to capture a long-run participation behaviour. Women who intend to participate over the life-cycle may not withdraw from the labour force during child rearing to avoid experience loss or simply because they are aware of the difficulties to become insider in the Spanish labour market.

\section{Effects of Husbands' Labour Market Status}

Little research has been conducted on the relationship between husband's and wife's labour market status with Spanish data. What evidence we have is dated and not conclusive. Moltó and Uriel (1986) used Employment Office (INEM) data from 1978 to 1984 and found "reasonable evidence of an added worker effect". In the following model specification, I assume husband's labour market status is exogenous.

In model (3) in Table 6, I use static measures of husband's employment status to estimate wives' mobility. In the exit equation there is no significant effect, which suggests that wives' withdrawal from the labour force is not driven by husbands' labour status. In the entry equation, the probability is positively affected by husbands' unemployment, and negatively affected by husbands' employment. The effect of husbands' employment is similar 
to that of medium size district, and thus smaller than husbands education: women married to employed men are $8 \%$ less likely to enter than otherwise inactive women (recall that the negative effect of husbands' education ranges from $22 \%$ for upper secondary husbands to $13 \%$ for lower secondary husbands), while women married to unemployed men are $10 \%$ more likely to enter. More importantly, the effect husbands' unemployment is the first positive impact found on the entry equation among all the effects considered in Tables 4, 5 and 6 . Thus, among all the effects seen so far, it is the single strongest predictor of entry despite of not being very big.

\section{Table 6}

Logit Model of Transition Probabilities

The Effects of Husband's Labour Market Status

(Static Measures, at time $t-1$ )

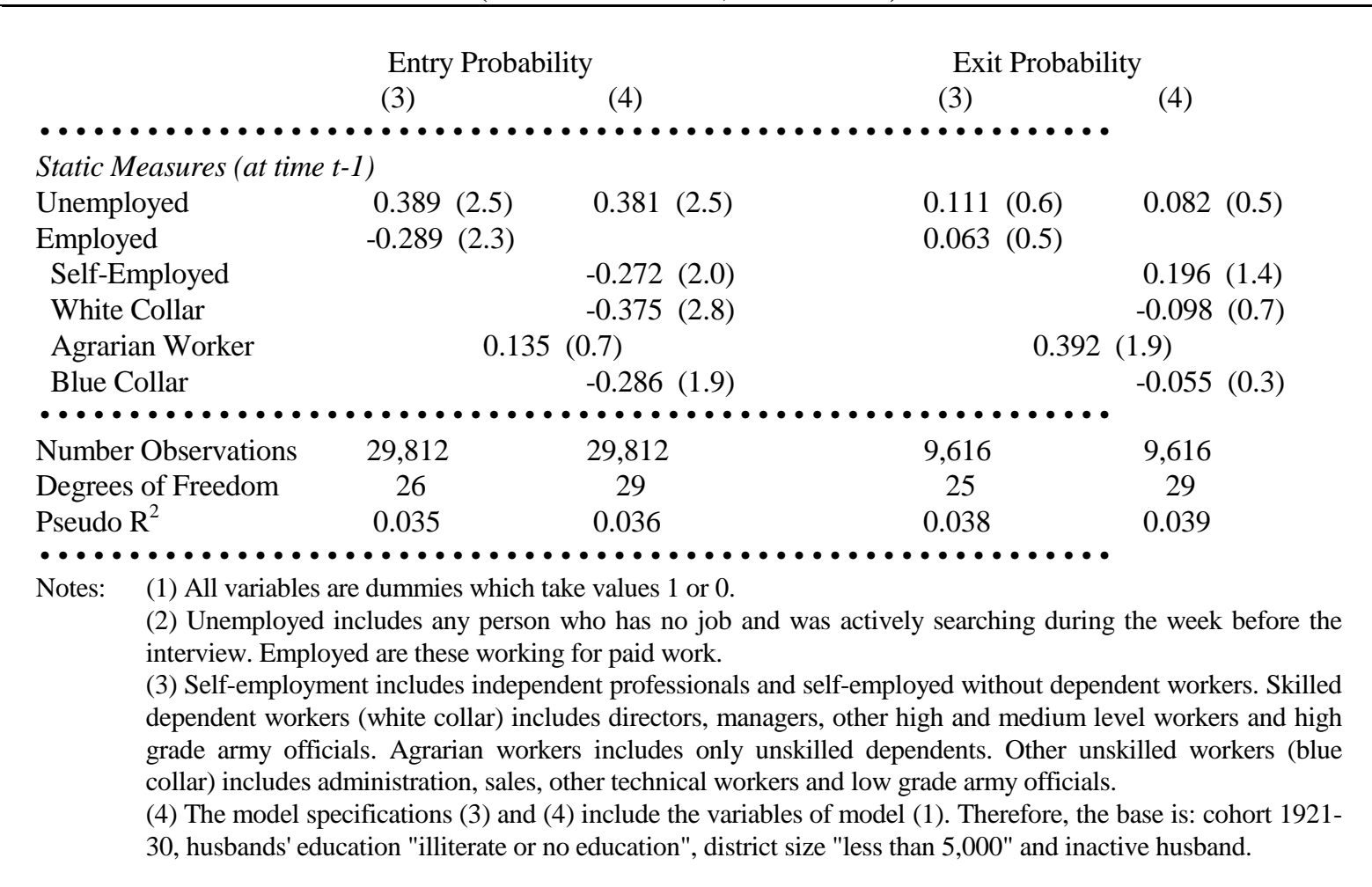

Because the "employment" variable is too vague, I present in model (4) a specification with different categories of employment. Among all the categories, white collar and professional husbands is the only one to show a strong and significant effect on wives' entry probability. For "self-employed" husbands, the coefficient is of similar size to that of white 
collar husbands, but less significant. Therefore, husbands' employment effect in model (3) is clearly driven by "self-employment" and "white collar" status. Comparing this with previous findings, note that husbands' education reduces more the entry probability than husband's employment: the effect of white collar status is twice as high as that of secondary school.

These results may not hold, however, if we take into account the insider-outsider division among employed. As described in Section 4, the widely used temporary contracts offer little job stability. The model specification of Table 6 does not really allow us to capture this feature of the Spanish labour force. Nonetheless, women's entry and exit probability may well be affected by such situations. Given that the ECPF does not provide information on the type of contracts, I use an alternative measure to capture the insiders (with permanent contracts) and the outsiders (with temporary contracts or unemployed). One of the major effects of the dualization of the Spanish workforce is the rise of labour rotation among outsiders which is, of course, not reflected among insiders. I use the panel structure of the ECPF survey to measure husbands' labour rotation (i.e. transitions to employment, to unemployment and from the labour force) as a proxy of outsiders. To avoid measurement errors due to transitions to retirement, I consider only husbands younger than 55 . 
Table 7

Logit Model of Transition Probabilities

The Effects of Husbands' Employment Rotation

(from t-1 to t)
Entry Probability
Exit Probability
(5)
(6)
(5)
(6)

Dynamic Measures (from $t$-1 to t)

\begin{tabular}{|c|c|c|c|c|}
\hline Entry Employment & \multicolumn{2}{|c|}{$0.966(6.3)$} & \multicolumn{2}{|c|}{$0.754(4.5)$} \\
\hline Entry Unemployment & \multicolumn{2}{|c|}{$0.499(2.3)$} & \multicolumn{2}{|c|}{$0.460(2.2)$} \\
\hline Exit the Labour Force & \multicolumn{2}{|c|}{$1.052(4.6)$} & \multicolumn{2}{|c|}{$0.697(2.4)$} \\
\hline Change of Status & \multicolumn{2}{|c|}{$0.772(7.3)$} & \multicolumn{2}{|c|}{$0.572(4.9)$} \\
\hline \multicolumn{5}{|c|}{ 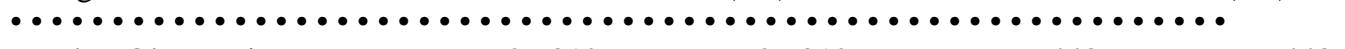 } \\
\hline Number Observations & 29,812 & 29,812 & 9,448 & 9,448 \\
\hline Degrees of Freedom & 27 & 25 & 27 & 25 \\
\hline Pseudo $\mathrm{R}^{2}$ & 0.037 & 0.036 & 0.043 & 0.042 \\
\hline
\end{tabular}

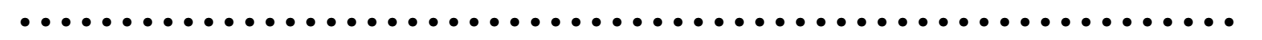

Notes: (1) All variables are dummies which take values 1 or 0.

(2) "Change of Status" refers to these whose labour market status (employed, unemployed or out-of-the-labourforce) changes from $t-1$ to $t$ in model (4) and from $t-2$ to $t-1$ in model (6).

(3) The model includes the variables of model (1), Table 5.

Table 8

Logit Model of Transition Probabilities

The Effects of Husbands' Employment Rotation

(from t-2 to t-1)

Entry Probability Exit Probability

(7)

(8)

(7)

(8)

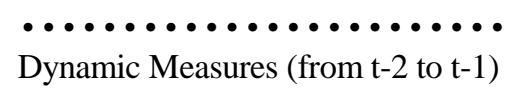

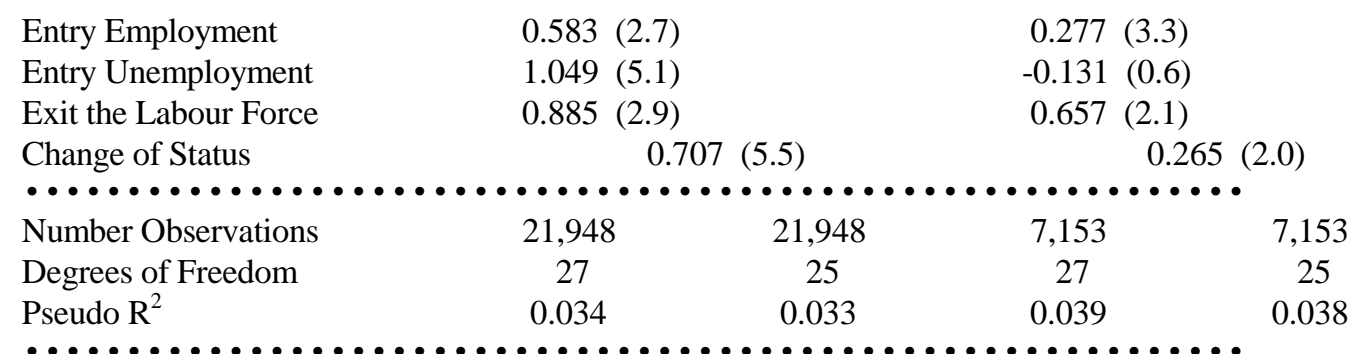

Notes: (1) All variables are dummies which take values 1 or 0.

(2) "Change of Status" refers to these whose labour market status (employed, unemployed or out-ofthe-labour-force) changes from $t-1$ to $t$ in model (4) and from $t$ - 2 to $t-1$ in model (6).

(3) The model includes the variables of model (1), Table 5. 
Model (5) in Table 7 reports the results. The selected husbands' transitions are: "entry employment", "entry unemployment" and "exit the labour force" ${ }^{17}$. These are assumed to be exogenous, and are measured from $t-1$ to $t$, that is, during the same time interval as wives' transitions'. The results are very interesting. The effects of any husbands' transition on any wive's transition are all large, positive and significant. One way to interpret this is to account for each case. For instance, one could interpret the positive effect of husbands' entry into employment on wives' exit probability, and the positive effect of husbands' entry into unemployment on wives' entry probability as an "added worker effect". The positive effect of husbands' entry into employment on wives entry probability and the positive effect of husbands' entry into unemployment on wives' exit probability, can be interpreted as an "encouraged (discouraged) worker" effect. However, in my opinion, there is a more interesting interpretation which is consistent with the reality of the Spanish labour market. Husbands' rotation affect wives' mobility and, thus, also wives' rotation. To assess this result, I use in model (6) in Table 7 different specification with one dummy that takes value 1 if the husband has changed labour market status. The results are similar to that of model (5).

Now, the results reported in Table 7 may have problems due the exogeneity assumption of husbands' transitions because these are measured in the same time interval as wives'. Table 8 shows the results of the same specification as in Table 7, with the only difference that husbands' transitions are lagged one period ${ }^{18}$. Therefore, I control for possible endogeneity. The results do not change substantially. There is, in the exit probability, a loss of

\footnotetext{
17 The reason why these three transitions have been selected is that they as they present the lowest cross-correlation coefficients. Therefore, they are unlikely to present collinearity problems.

${ }^{18}$ The reader may realize that the sample size decreases with the specification of Table $7 \mathrm{~b}$. This is because of attrition. The number of households responding to three consecutive interviews is lower than the number of households responding to two (Adam, 1995c).
} 
significance and a reduction in the size of the estimates, particularly the coefficient of "entry into unemployment". In the entry equation, the coefficient for "entry into unemployment" gains significance and size, while the remainders do the opposite. Overall, the results of Table 8 confirm that the mobility of husbands increases the mobility of wives. 


\section{Conclusions}

This study considers three features of the Spanish economy to analyze married women's labour force transitions. One, the structural change in terms of women's participation over the life-cycle, promoting a growth of women who intend to participate in the long-run. Two, the existence of a male breadwinner model which does not encourage women to reenter the labour force after childbirth. Three, the effects of husbands' employment situation as a result of the increasing dualization of the Spanish labour force between insiders (with stable permanent jobs) and outsiders (with high labour mobility).

The model used for the parametric analysis of transitions turns out to be a very convenient model for its easy and flexible interpretation. In particular, the distinction between 'mover-stayer' effects and 'pro-participation' and 'pro-inactivity' effects has revealed interesting results about the forces underlying the labour forces moves of married women. Nonetheless, unobservable factors have a huge impact on the transition probabilities (considering the low pseudo- $\mathrm{R}^{2}$ obtained), much bigger than the observables. Part of this has to do with the non inclusion of presumably important variables such as wives' education and region of residence. Considering the identified effects given observable characteristics, the results that emerge from my estimations are the following.

Like in other countries with Male Breadwinner regimes, Spanish mothers tend to withdraw from the labour force after childbirth and during the time children are preschoolers. However, unlike these other countries, Spanish mothers do not re-enter after their children arrive at school age. This seems to be less so among long-run participant mothers in the younger cohorts. Not having been able to test directly for long-run participation versus a priori non-participating women through controls for education, I have used husbands' education as a proxy. The results show, indeed, that the effects of children are not as described above for higher educated husbands. 
Children are clearly the main cause of mothers' withdrawals from the labour force, However, children seem to have little influence on women's entry or re-entry. Instead, married women's labour force entry appears related to husband's employment uncertainty (measured through labour transitions and unemployment). The size of this effect is almost as large as the positive effect of children in the exit probability.

The polarization of the Spanish labour force between insiders and outsiders affects the overall mobility patterns of husbands and wives. It divides husbands into a core of permanently employed (insiders) and a stratum of mobile, rotating outsiders. It is in this context that I understand married women's behaviour. Married women in an "insider household" are less likely to be mobile than women in an "outsider household". In the former case, childbirth is likely to result in permanent exit among the a priori non-participants. In the latter case, childbirth is less likely to result in permanent exit among the a priori nonparticipants. In contrast, long run participating women are much less affected by husband's insider-outsider status and by childbirth. 


\section{Appendix}

Descriptive Statistics of Some Important ECPF Variables.

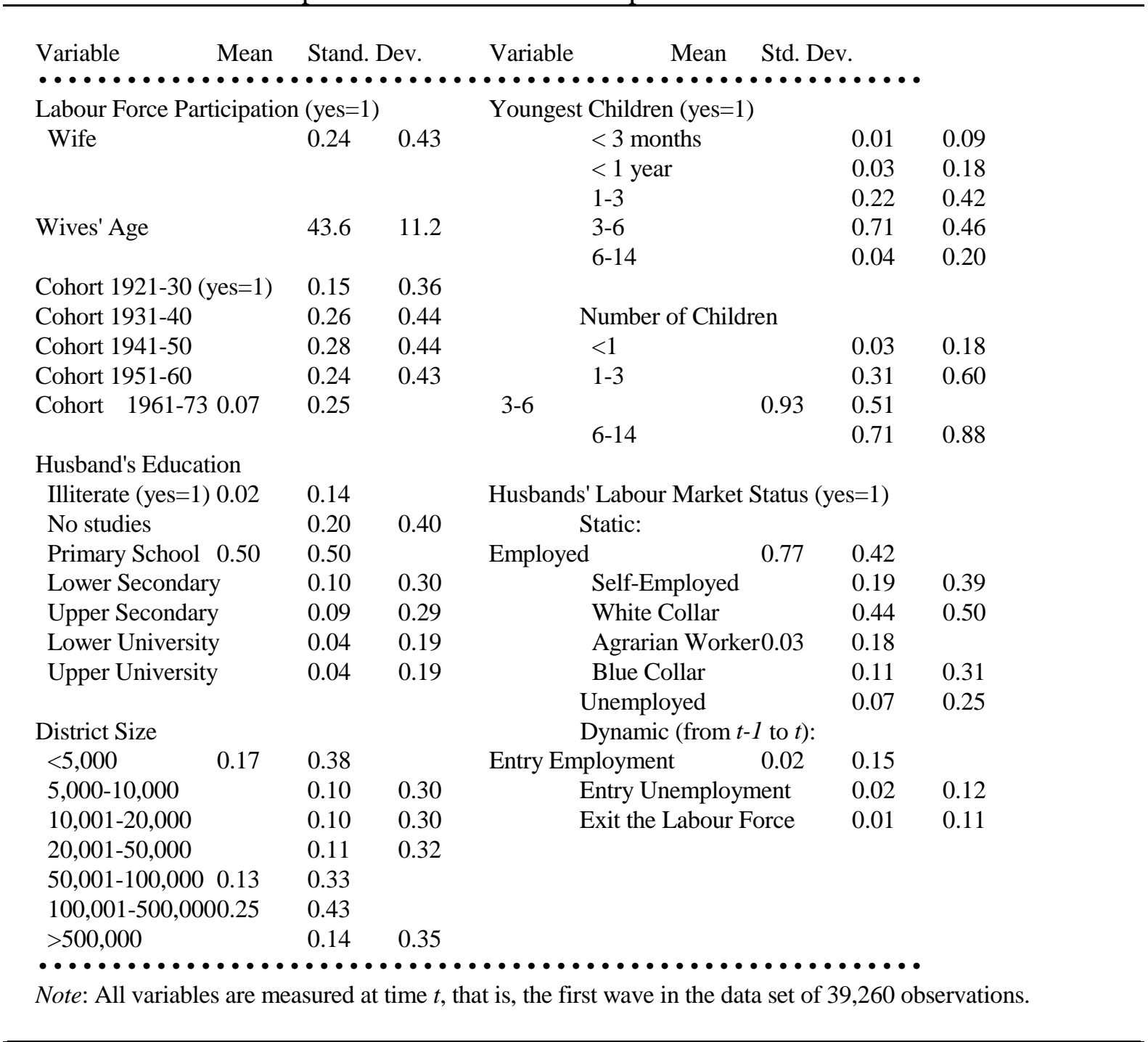




\section{References}

Adam P (1995a) Transiciones Laborales de la Mujer Casada: Determinantes de la Movilidad. In: Dolado J and JF Jimeno (Ed) Estudios sobre el Funcionamiento del Mercado de Trabajo Español. Colecciones FEDEA.

Adam P (1995b) Women and Work in the OECD: Is Spain Really the Exception?. Miemo, European University Insitute, Florence, Italy.

Adam P (1995c) The Use of the ECPF for Labour Market Research. In: "Married Women's Labour Force Transitions in Spain" (provisional title), Doctoral Thesis, European University Insitute, Florence, Italy. Chapter 2. (forthcoming)

Ahn N, Ugidos-Olazabal A (1994) Duration of Unemployment in Spain: Relative Effects of Unemployment Benefit and Family Characteristics. ???

Albarracin J, Artola C (1989) Oferta y Demanda de Trabajo en el Período 1977-1988. Boletín Económico, Banco de España, July 103-114.

Amemiya T (1985) Advanced Econometrics. Chapter 11. Oxford Blackwell.

Arellano M, Bover O (1994) Female Labour Force Participation in the 1980s: The Case of Spain. Investigaciones Económicas, Segunda Epoca, Vol XIX(2), May.

Bentolila S, Dolado J (1994) Labour Flexibility and Wages: Lessons from Spain, CEMFI Working Paper 9406, Madrid.

Browning M (1992) Children and Household Economic Behavior. J Econ Lit, Vol XXX (sept), 1434-1475.

Deaton and Muellbauer (1980) Economics and Consumer Behavior. Chapter 11. Cambridge University Press.

Greene WH (1993) Econometric Analysis, 2nd Edition, New York: Macmillan.

Gustafsson S, Vlasblom JD, Wetzels C (1995) Women's Labour Force Transitions in connection with Child Birth. A Comparison between Germany and Sweden. Paper presented at the X Annual Meeting of the ESPE at Lisbon.

Gustafsson S, Stafford FP (1994) Three Regimes of Child Care: The United States, the Netherlands and Sweden. In: Blank RM (Ed) Social Portection versus Economic Flexibility. Is there a Trade-off? University of Chicago Press, Chicago.

Heckman J (1974) Effects of Child-Care Programs on Women's Work Effort, J Polit Econ, March-April, 82(2, Part II), pp S136-63. 
Jimeno JF, Toharia L (1993) The Effects of Fixed-Term Employment on Wages: Theory and Evidence from Spain. Investigaciones Económicas, Vol XVII(3):475-494.

Johnston J (1984) Econometric Methods, 3rd Edition, New York: McGraw-Hill.

Lehrer E, Nerlove M (1986) Female Labor Force Behavior and Fertility in the United States. Ann Rev Sociology, 12, 181-204.

Lindbeck A, Snower D (1988) The Insider-Outsider Theory of Employment and Unemployment. The MIT Press: Cambridge Mass, London (England).

Martínez M (1994) An Empirical Model of Female Labour Supply for Spain. CEMFI Working Paper 9412.

Moltó ML, Uriel E (1986) Análisis Bayesiano de la Incidencia del Paro Masculino sobre la Demanda de Empleo Femenina. Cuadernos Económicos del ICE, 34, 1986/3.

Nakamura A, Nakamura M (1992) The Econometrics of Female Labor Supply and Children. Econ Rev, 11(1), 1-71, 93-96.

Novales, A (1989) La Incorporación de la Mujer en el Mercado de Trabajo en España: Participación y Ocupación. Moneda y Credito, $2^{\mathrm{a}}$ epoca, 188.

Novales A, Mateos B (1990) Actividad Económica y Participación Laboral de las Mujeres y los Jóvenes. In: Estudios Sobre Participación Activa, Empleo y Paro en España. Ed. FEDEA.

OECD (1990) Employment Outlook, Chapter 5.

OECD (1994) Women and Structural Change: New Perspectives. Chapter 3, Paris.

Ondrich , Spiess , Yang (1995)

Revenga A (1994) Aspectos Microeconomicos del Mercado de Trabajo Español. In: Blanchard O, Jimeno JF (Ed) EL Paro en España: Tiene Solución?. CEPR.

Segura J, Duran F, Toharia L, Bentolila S (1991) Análisis de la Contratación Temporal en España. Ministerio de Trabajo y Seguridad Social, Madrid.

Sundström , Rönsen (1995)

Von der Laan L (1995) Gender and Labour Market Participation: an Analysis of Future Developments in the Regions in the European Union. Erasmus Centre for Labour Market Analysis, NL. Mimeo. 